\title{
Sr-substitution Effects on La-NiO3, Sol-Gel Synthesis, Structural and Electrical Properties
}

\author{
M. Sh. Khalil and M. A. Wahba \\ Inorganic Chemistry Department, National Research Centre, \\ Dokki, Cairo, Egypt.
}

\begin{abstract}
T $\mathrm{N}$ ORDER to investigate Sr-substitution effects on LaNiO3, LSN, properties, thermal analysis, $\mathrm{x}$-ray diffraction, and scanning electron microscopy studies were used to characterize powder samples of $\mathrm{La}_{1-\mathrm{x}} \mathrm{Sr}_{\mathrm{x}} \mathrm{NiO}_{3}, \mathrm{x}=0,0.3,0.5,0.8$ and 1, prepared by the sol-gel route via the polymerized complex method. Electrical conductivity and dielectric properties of the different compositions were also done. Samples of the complex solutions of molar ratios $\mathrm{La}(\mathrm{Sr}) / \mathrm{Ni} /$ citric acid (CA)/ethylene glycol $(\mathrm{EG})=1: 1: 10: 40$, were heated at $130^{\circ} \mathrm{C}$ to reach a gel form, dried at $350^{\circ} \mathrm{C}$, crushed to the precursor powder LSN, then final calcination was performed at $800^{\circ} \mathrm{C} / 2 \mathrm{hr}$ in air according to thermal analysis results. Elemental analysis through the EDS spectroscopy confirms the compositions. Ultrafine, nanoparticle samples having perovskite $(\mathrm{ABO} 3)$ tetragonal crystalline were formed except that of $\mathrm{x}=1, \mathrm{SrNiO}_{3}$, which has a cubic one. The conduction mechanism changes from semi-conductive to metallic as $\mathrm{Sr}$ incorporation increases and, $\sigma$ seems to be temperature independent, while the dielectric values increase.
\end{abstract}

Keywords: $\mathrm{SrLaNiO}_{3}$, Perovskite, Sol-gel, Characterization, Electrical conductivity

Composite materials made of $\mathrm{La}, \mathrm{Sr}$ and $\mathrm{Ni}$ mixed oxides in the form $\mathrm{La}_{1-\mathrm{x}}$ $\mathrm{Sr}_{\mathrm{x}} \mathrm{NiO}_{3}, \mathrm{LSN}$, have the perovskite type structure of the form $\mathrm{ABO}_{3}$. These oxides are potentially attractive for use in catalysis for complete combustion of hydrocarbons ${ }^{(1,2)}$ and as cathode electrodes in fuel cells ${ }^{(3)}$. As well, they are used as ceramic conductive materials where they exhibit a wide range of properties as metallic and semi-conductive ones ${ }^{(4)}$. LSN, also find a wide range of application as chemically sensitive materials for sensors ${ }^{(5,6)}$. Tsipis et al. ${ }^{(7)}$, Chiba et al. ${ }^{(8)}$ investigated $(\mathrm{La}, \mathrm{Sr})(\mathrm{Ni}, \mathrm{Fe}) \mathrm{O}_{3}$ perovskites as promising cathodes since they possess attractive electronic conductivity. It was reported that the influence of $\mathrm{Sr}^{2+}$ and $\mathrm{Ni}^{2+}$ ions incorporation concentrations in the A-sites of $\mathrm{ABO}_{3}$ peroveskite systems enhance the efficiency of being used as cathodes for fuel cell ${ }^{(3)}$. In previous studies ${ }^{(9-11)}, \mathrm{La} / \mathrm{B}-\mathrm{CoO}_{3}$ systems were synthesized, characterized and as well, the electrical properties of the ceramic systems were investigated. Few studies have been recorded for studying the composition $\mathrm{La}_{1-\mathrm{x}} \mathrm{Sr}_{\mathrm{x}} \mathrm{NiO}_{3}$ and no detailed data are available concerning electrical conductivity and dielectric properties of those ceramic composite systems. 
In this communication, focus was done to study the crystalline particle structures of LSN systems synthesized by the in-situ polymerization sol-gel technique proposed by Pechini ${ }^{(12)}$. Thermal analysis of the precursor powder dried at $350^{\circ} \mathrm{C}$, and XRD patterns, SEM images as well as electrical properties of the ceramic samples calcined at $800^{\circ} \mathrm{C} / 2 \mathrm{hr}$ were studied and discussed.

\section{Experimental}

\section{Sample preparation and measurements}

Available commercial of analytical grade salts of $\mathrm{LaCl}_{3}-7 \mathrm{H}_{2} \mathrm{O}, \mathrm{NiNO}_{3}-2 \mathrm{H}_{2} \mathrm{O}$ in addition to $\mathrm{Sr}\left(\mathrm{NO}_{3}\right)_{2}$ were used according to the required molar ratios. Five, $\mathrm{La}_{(1-\mathrm{x})} \mathrm{Sr}_{(\mathrm{x})} \mathrm{NiO}_{3}$ aqueous solution samples with $\mathrm{x}=0,0.3,0.5,0.8$ and 1 , were prepared. Citric acid (CA) as a chelating agent and ethylene glycol (EG) as a complexing one were used in the molar ratios of $\mathrm{La} / \mathrm{Ni} / \mathrm{CA} / \mathrm{EG} 1: 1: 10: 40$ as proposed by Pechini and Kakihana through the in-situ sol-gel technique ${ }^{(12)}$, which involved mixing stoichiometric amounts of $\mathrm{Sr} / \mathrm{La} / \mathrm{Ni}$ salts with $\mathrm{CA}$ in an aqueous medium. Solutions of $\mathrm{LaCl}_{3}-7 \mathrm{H}_{2} \mathrm{O}, \mathrm{NiNO}_{3}-2 \mathrm{H}_{2} \mathrm{O}$ in addition to $\mathrm{Sr}\left(\mathrm{NO}_{3}\right)_{2}$ salts in the desired mole $\%$ were added dropwise to a constantly stirred aqueous solution of the carboxylic acid. Ammonia hydroxide solution was then added drop by drop under continuous stirring. Addition of the diluted basic solution (typically $\mathrm{NH}_{4} \mathrm{OH}$ ) accelerates the hydrolysis process. After then, the $\mathrm{pH}$ of the sol is neutralized gradually to $7, \mathrm{EG}$ was then added as a complexing agent which stimulates the gelation process. At this stage a mechanically unstable wet gel is formed. The resulted solution was then vaporized at $130^{\circ} \mathrm{C}$ under magnetic stirring until a xerogel was obtained. The formed xerogel precursor was decomposed at $350{ }^{\circ} \mathrm{C}$ in an electric dry furnace in air to get rid of the organic substances, and left to cool to room temperature. The decomposed powders were slightly milled using a mortar and calcined in air at $800{ }^{\circ} \mathrm{C}$ for $2 \mathrm{hr}$ and naturally cooled to room temperature.

\section{Characterization methods}

Thermogravimetric analysis of the prepared samples was conducted using a Perkin-Elmer Delta series (TGA7) thermoanalyzer. The rate of heating was $10^{\circ} \mathrm{C}$ $\mathrm{min}^{-1}$, in a flow of static air. The phase composition of samples was determined using $\mathrm{XRD}$ in the range of $2 \theta\left(20-100^{\circ}\right)$ at room temperature, with a step increase of $0.02^{\circ}$ using an XRD diffractometer (X'Pert PROdiffractometer, $\mathrm{Cu} \mathrm{K \alpha}$ radiation; PANalytical BV, Almelo, The Netherlands). Based on the XRD patterns, the average crystallite size was determined using the Scherrer's formula, and lattice parameters were calculated by the Match software using the Rietveld method ${ }^{(13)}$. The morphology of the obtained samples was investigated by using scanning electron microscopy and energy-dispersive spectroscopy (EDS) (Ultra Plus; Carl Zeiss Meditec AG, Jena, Germany).

\section{Electrical measurements}

The Dc logarithmic seal, electrical measurements, of the line powder sieved through 0.2 mesh to avoid different grain boundary conductance were taken by

Egypt. J. Chem. 59, No. 5 (2016) 
means of a two-probe method on compressed centered disks $(1 \mathrm{~cm}$ diameter and 3 mm thickness) using LCR HIOKI 3532 HiTESTER instrument (Japan).

\section{Results and Discussions}

\section{Thermal analysis}

Gravimetrical thermal analysis, TG curves of the dry gel precursors of samples LSN were shown in Fig. 1. Curves show the predominance of exothermic transformations. Three peaks were observed at 60-150 and 440-600 assigned respectively to water loss and decomposition of the gel metal organic citrates volatile products in order to form metal: $\mathrm{La}, \mathrm{Ni}, \mathrm{Sr}$ oxides. The last peak concerns transformation of the oxides, occurred at $600-700^{\circ} \mathrm{C}$ till $800^{\circ} \mathrm{C}$ is accompanied by a weight gain due to the final rearrangement of the perovskite $\mathrm{ABO}_{3}$ type structure LSN according to their molar ratios. No longer have thermal changes been recorded.

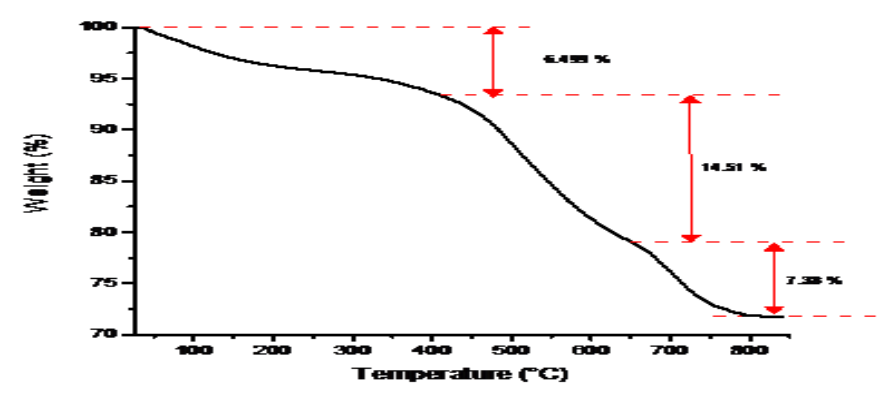

Fig. 1. Thermogravimetric curve of $\mathrm{Sr}_{0.5} \mathrm{La}_{0.5} \mathrm{NiO}_{3}$ sample.

\section{Powder characterization:}

\section{$X R D$}

XRD patterns for powder samples, LSN calcined at $800{ }^{\circ} \mathrm{C} / 2 \mathrm{hr}$ are shown in Fig. 2. Patterns correspond mainly to the perovskite type structure; show the tetragonal crystal structure for all samples except pure $\mathrm{SrNiO}_{3}$ sample which appears cubic. The particle size, calculated by Scherer equation, clearly decreases as $\mathrm{Sr}$ ion-addition increases, it ranged between $39-57 \mathrm{~nm}$ for the Sr-substituted samples except pure cubic $\mathrm{SrNiO} 3$ sample which records over than $100 \mathrm{~nm}$ (Table 1). XRD patterns show high intensity peaks at $2 \theta: 31^{\circ}-32^{\circ}-33^{\circ}$, then small ones at $47^{\circ}, 58^{\circ}$ indicating highly crystalline products for pure $\mathrm{LN}$, but shifted to high $2 \theta$ values as the molar ratio (x) of $\mathrm{Sr}$ increased. Pure peaks related to $\mathrm{SrNiO}_{3}$ were observed at $2 \theta=38^{\circ}$ and $58^{\circ}$. There were also some diffraction lines of low intensities other than the perovskite ones indexed to separate parent oxides of $\mathrm{La}$, $\mathrm{Ni}$ and $\mathrm{Sr}$ at $2 \theta=24^{\circ}, 36^{\circ}$ and $47^{\circ}$ which is in accordance with that reported by Cruz et al. ${ }^{(3)}$ 


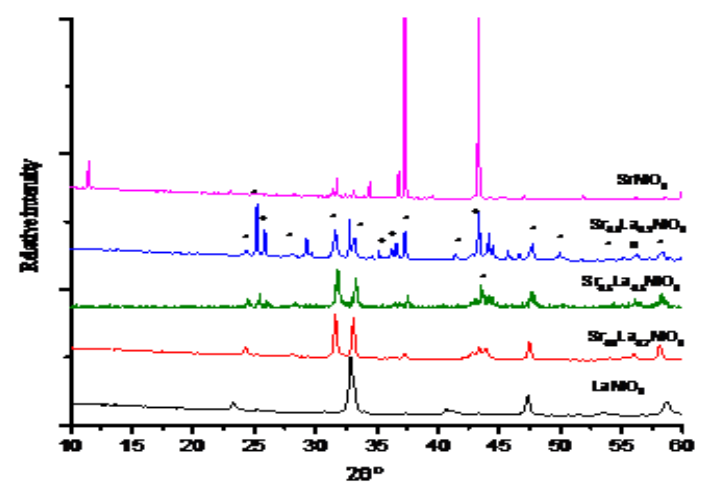

Fig. 2. X-ray diffractograms of $\mathrm{Sr}_{x} \mathrm{La}_{1-x} \mathrm{NiO}_{3}$ samples (x=0, $0.3,0.5,0.8,1.0$, Substitution degrees are indicated within the figure $(*)$ perovskite; (n )NiO; (+) SrO.

TABLE 1. XRD data of $\mathrm{Sr}_{x} \mathrm{La}_{1-\mathrm{x}} \mathrm{NiO}_{3}$ samples prepared by sol gel method as function of iron content.

\begin{tabular}{|c|c|c|c|c|c|}
\hline \multirow{2}{*}{ Sample } & \multicolumn{4}{|c|}{ Direct cell parameters } & \multirow{2}{*}{$\begin{array}{c}\text { Crystallite size } \\
\text { (nm) }\end{array}$} \\
\hline & $\mathbf{a}(\stackrel{\AA}{\mathbf{A}})$ & $\mathbf{b}(\AA)$ & $\mathbf{c}(\AA)$ & $\mathbf{v}(\AA)$ & \\
\hline $\mathrm{La}_{1} \mathrm{NiO}_{3}$ & 5.4578 & 5.4578 & 13.18855 & 340.2174 & 39.6 \\
\hline $\mathrm{Sr}_{0.3} \mathrm{La}_{0.7} \mathrm{NiO}_{3}$ & 3.8307 & 3.8413 & 12.9651 & 186.8151 & 57.3 \\
\hline $\mathrm{Sr}_{0.5} \mathrm{La}_{0.5} \mathrm{NiO}^{3}$ & 3.8679 & 3.7344 & 12.6526 & 182.7540 & 55.6 \\
\hline $\mathrm{Sr}_{0.8} \mathrm{La}_{0.2} \mathrm{NiO}_{3}$ & 3.815 & 3.815 & 12.7131 & 185.0487 & 44.11 \\
\hline $\mathrm{SrNiO}_{3}$ & 4.1786 & 4.1786 & 4.1786 & 72.9618 & $>100$ \\
\hline
\end{tabular}

\section{SEM}

The nanocrystalline samples, LSN prepared by the thermal decomposition of metal polymerized complex solutions show smaller particles of homogeneous distribution, as shown by SEM micrographs, (Fig. 3). Samples appear as porousfoam-like agglomeration, with narrow distribution of nanoparticle sizes compatible with those calculated by Scherrer equation.
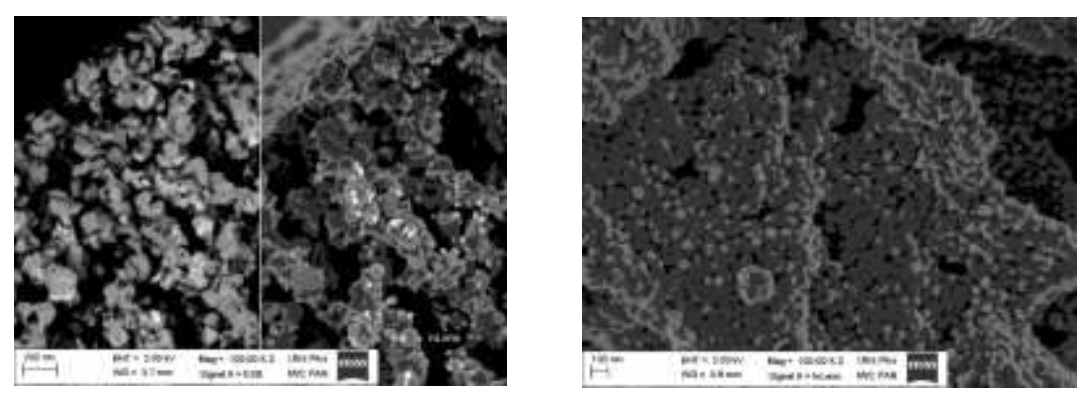

Egypt. J. Chem. 59, No. 5 (2016) 

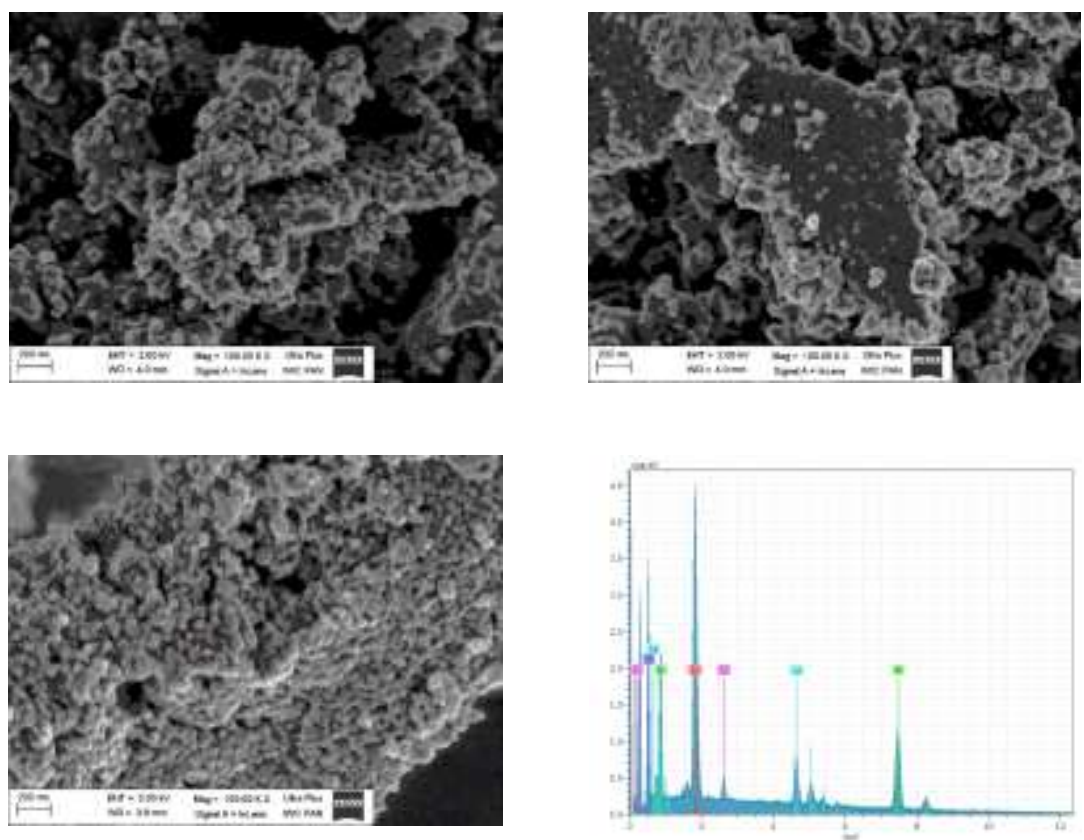

Fig. 3. SEM micrographs of a) $\mathrm{LaNiO}_{3}$, b) $\mathrm{Sr}_{0.3} \mathrm{~L} \mathrm{a}_{0.7} \mathrm{NiO}_{3}$, c) $\mathrm{Sr}_{0.5} \mathrm{La}_{0.5} \mathrm{NiO}_{3}$ d) $\mathrm{Sr}_{0.8} \mathrm{La}_{0.2} \mathrm{NiO}_{3}$, e) $\mathrm{SrNiO}_{3}$ samples, f) $\mathrm{EDX}$ of $\mathrm{Sr}_{0.8} \mathrm{La}_{0.2} \mathrm{NiO}_{3}$ sample.

The segregation of La-Sr components in LSN samples is observed to increase with increasing $\mathrm{Sr}^{2+}$ incorporation content. It indicates that the solubility of $\mathrm{Sr}^{2+}$ in the crystal structure has reached its limit at high substitution percent since the ionic radius of ${ }^{\mathrm{Sr} 2+}(0.144 \mathrm{~nm})$ is less than that of $\mathrm{La}^{3+}(0.136 \mathrm{~nm})^{(3)}$. Energy dispersive spectrometry, EDS, for elemental analysis of $\mathrm{La}, \mathrm{Sr}, \mathrm{Ni}$ and $\mathrm{O}$ confirms the composition of sample $\mathrm{La}_{0.2} \mathrm{Sr}_{0.8} \mathrm{NiO}_{3}$ with small traces of 0.00029 molar \% chlorides still present as shown in the Fig. 3 and Table 2.

TABLE 2. Composition ratios in mole per mole of $\mathrm{Sr} 0.8 \mathrm{La0.2NiO3}$ sample

\begin{tabular}{cccccc}
\hline $\mathrm{mol} / \mathrm{mol}$ & $\mathrm{Sr}$ & $\mathrm{La}$ & $\mathrm{Ni}$ & $\mathrm{O}$ & $\mathrm{Cl}-$ \\
\hline $\mathrm{Sr}_{0.8} \mathrm{La}_{0.2} \mathrm{NO}_{3}$ & 0.003 & 0.001 & 0.0063 & 0.013 & 0.00029 \\
\hline
\end{tabular}

\section{Electrical conductivity}

La3+-substitution by $\mathrm{Sr}^{2+}$ is expected to affect the studied electrical properties. Dependence of the electrical conductivity $\log \sigma\left(\Omega^{-1} \mathrm{~cm}^{-1}\right)$, of the sintered samples, LSN on the frequency $\left(100-5.10^{7} \mathrm{~Hz}\right)$ at constant temperature, $298 \mathrm{~K}$, is shown in Fig. 4, while $\sigma$ versus the reciprocal of the temperature in $K$, expressed by Arrhenius equation, at constant frequency, $10^{4} \mathrm{~Hz}$, is illustrated in Fig. 5. 
The conductivity $\log \sigma$, as a function of frequency $\log \mathrm{f}(\mathrm{Hz})$, at room temperature, (Fig. 4) shows that at low frequencies, all samples have $\sigma$ values in a wide range that increased obviously with frequency. A Conductivity/frequencyindependent relationship, nearly a straight line all over the frequency range is obtained for $\mathrm{x}=0$ but with higher $\sigma$ value, about $3 \Omega^{-1} \mathrm{~cm}^{-1}$, which is in accordance with data reported by Ganguly et al. ${ }^{(14)}$ where the conduction mechanism may be due to electron hopping between $\mathrm{Ni}^{2+}$ and $\mathrm{Ni}^{3+}$ ions. On the other hand, $\sigma$ decreases with $\mathrm{Sr}^{2+}$ ions additions for $\mathrm{x}=0.3,0.5$, and decreases obviously for $\mathrm{x}=$ 0.8 where the crystal lattice has reached the limit for different ionic radii.

On the other hand, Fig. 5 shows that $\sigma$ increased with increasing temperature regardless of $\mathrm{Sr}$ ratio (x) incorporation but, as $\mathrm{x}=1, \mathrm{SrNiO}_{3}$, a straight temperature independent line, is obtained. The conductivity of all samples shows a semiconductive behavior that is, it increased with temperature (intrinsic region) due to high mobility of oxide ions free charges and the inter-change valence electrons, except for $\mathrm{SrNiO}_{3}(\mathrm{x}=1)$ where the conduction mechanism changed from semiconductive to metallic of high and (nearly independent/temp) constant $\sigma$ values. This behavior may be due to the increased ratio $\mathrm{of} \mathrm{Sr}^{2+}$ ions of smaller sizes than that of $\mathrm{La}^{3+}$ ions, where the thermal energy is partially consumed in the rearrangement of a modified crystal structure, and not sufficient to excite the electrons in their conductance levels, that causes decrease of charge carriers ${ }^{(15)}$.

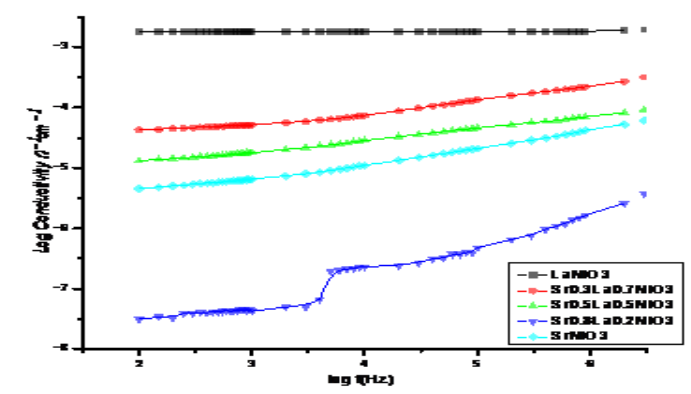

Fig. 4. Electrical conductivity vs. frequency at $298 \mathrm{~K}$, for different $\mathrm{Sr}_{\mathrm{x}} \mathrm{La}_{1-\mathrm{x}} \mathrm{NiO}_{3}$

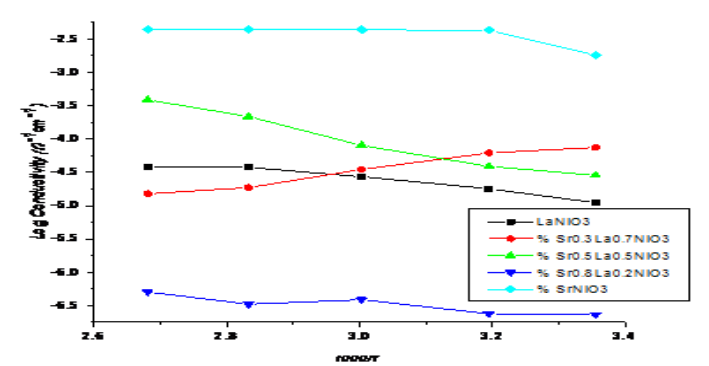

Fig. 5. Arrhenius plots of conductivity for $\mathrm{Sr}_{x} \mathrm{La}_{1-x} \mathrm{NiO}_{3}$ samples at $10 \mathrm{KHz}$.

Egypt. J. Chem. 59, No. 5 (2016) 
In general, it is clear that the conductivity decreases with $\mathrm{Sr}$ ions incorporation in $\mathrm{LaNiO}_{3}$, but with higher mobility as the frequency increased.

\section{Dielectric constant}

The dielectric constant values, $\varepsilon^{\prime}$, versus frequency $(100 \mathrm{~Hz}-5 \mathrm{MHz})$ at room temperature $\left(25{ }^{\circ} \mathrm{C}\right)$ (Fig 6) and versus temperature $\left(25-140{ }^{\circ} \mathrm{C}\right)$ at constant frequency $(10 \mathrm{KHz})$ (Fig. 7), for all LSN samples were given and discussed. Figures show substantial dielectric dispersion for the $\mathrm{Sr} 2+$ ion addition to $\mathrm{LaNiO} 3$ substance with minimum $\mathrm{Sr}$ content, but higher $\mathrm{Sr}$ contents reduce $\varepsilon^{\prime}$ values according to the order: $0.3>0.5>0.8$.

The dielectric constant values, $\varepsilon^{\prime}$, against frequency plot (Fig. 6) at constant temperature for all samples, show high values at low frequencies which decrease by increasing frequency to become nearly independent at higher frequencies. This behavior could be related to a decreasing number of dipoles that contributes to polarization as it can easily follow the electric field at low frequencies. As the frequency increases, the dipoles begin to lag the field (relaxation process increases) and the interlayer capacity and the related $\varepsilon^{\prime}$ decreases. On the other hand, incorporation of Sr ions into LN does increase $\varepsilon^{\prime}$ in higher values for smaller molar ratios (0.3>0.5) and in less extent, but still high, for $\mathrm{SrNiO}_{3}$ as pure perovskite dielectric material, while it decreases obviously for pure $\mathrm{LN}$ and $0.8 \mathrm{Sr}$ ion ratios which also still constant.

Variation of $\varepsilon^{\prime}$ with temperature, (Fig. 7) seems to be temperature independent for samples: LN, LS0.3N and LSo.8N, while $\varepsilon^{\prime}$ increased for $\mathrm{x}=0.5$ and $\mathrm{x}=1$ ( $\mathrm{SrNiO3})$, which may be due to greater freedom of the ionic movement at high temperatures that leads to increasing the polarization and hence the permittivity. West ${ }^{(16)}$ explained this behavior as space charge polarizability occurring in materials that are not perfect dielectrics. Dielectric absorption was not shown till $10 \mathrm{KHz}$ where the relaxation time and ionic species of the dielectric polarization are greatly reduced at low frequency.

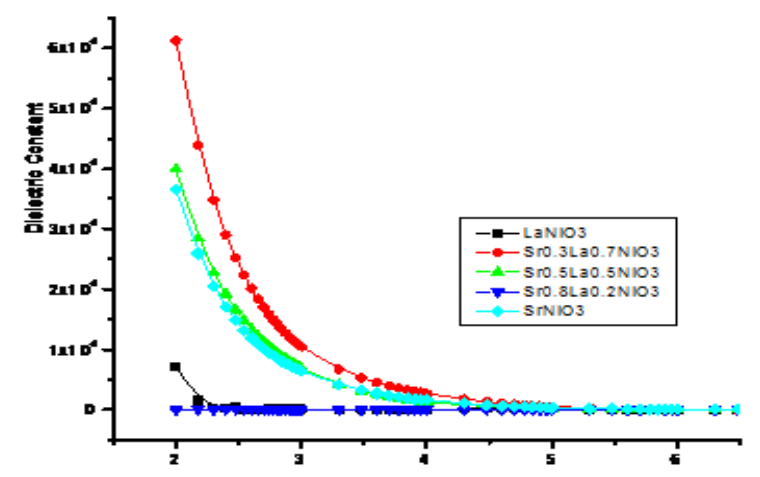

Fig. 6. Variation of dielectric constant as a function of frequency for SrxLa1-xNiO3 samples at $289 \mathrm{~K}$. 


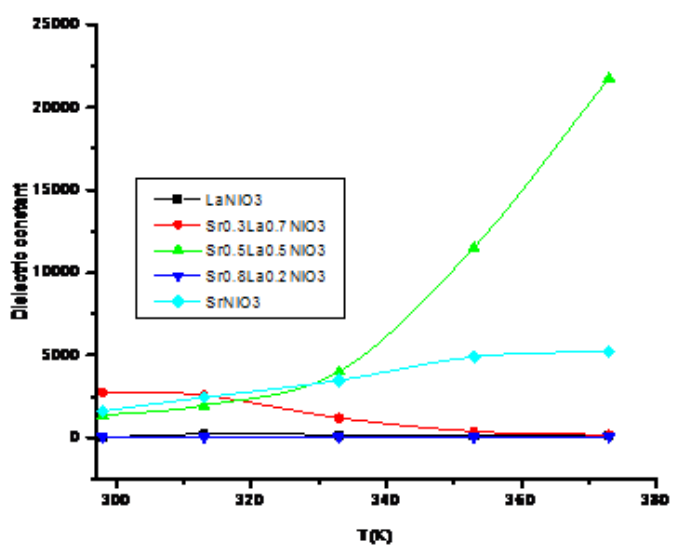

Fig.7. Variation of dielectric constant as a function of temperature for SrxLa1-xNiO3 samples at $10 \mathrm{KHz}$.

\section{Conclusion}

The $\mathrm{La}_{1-\mathrm{x}}\left(\mathrm{Sr}_{\mathrm{x}}\right) \mathrm{NiO}_{3}$ samples of perovskite form $\mathrm{ABO} 3$, have been synthesized by the sol-gel procedure using the Pechini-Kakihana polymerized complex technique, which has the advantage of preparing a ceramic semiconducting material at calcination temperature as low as possible. Stable single phases of the desired structures have been formed at about $800{ }^{\circ} \mathrm{C}$ at which, prepared samples were sintered for $2 \mathrm{hr}$ and characterized. Substitution of $\mathrm{Sr}$ for $\mathrm{La}$, in some extents, enhances and changes electrical ionic and electronic conductance as well as the dielectric properties.

\section{References}

1. Lima, S.M.d. and Assaf, J.M., Synthesis and Characterization of $\mathrm{LaNiO}_{3}, \mathrm{LaNi}_{(1-\mathrm{x})}$ $\mathrm{Fe}_{\mathrm{x}} \mathrm{O}_{3}$ andLaNi (1-x) $\mathrm{Co}_{\mathrm{x}} \mathrm{O}_{3}$ Perovskite Oxides for Catalysis Application, Materials Research, 5, (2002) 329-335.

2. Gao, Z., Mao, Z., Wang, C. and Liu, Z., Preparation and characterization of $\mathrm{La}_{1-\mathrm{x}}$ SrxNiyFe $1-$ y $\mathrm{O} 3-\delta$ cathodes for low-temperature solid oxide fuel cells. International Journal of Hydrogen Energy, 35, 12905-12910 (2010).

3. De la Cruz, R.G., Falcon, H., Pena, M. and Fierro, J., Role of bulk and surface structures of $\mathrm{La} 1-\mathrm{x} \mathrm{Sr} \times \mathrm{NiO} 3$ perovskite-type oxides in methane combustion. Applied Catalysis B: Environmental, 33, 45-55 (2001).

4. Kim, D.J., Shen, D., Yoon, S.H., Choe, S.Y. and Kaufman, D.Y., Effect of Ru and LaNiO3 barrier layers on lead zirconate titanate films grown on nickel-based metal foils by sol-gel process. Ceramics International, 34, 1261-1265 (2008).

Egypt. J. Chem. 59, No. 5 (2016) 
5. Chiu, C. and Chang, Y.H., The influence of microstructure and deposition methods on $\mathrm{CO}$ gas sensing properties of $\mathrm{La} 0.8 \mathrm{Sr} 0.2 \mathrm{Co}_{1-\mathrm{x}} \mathrm{Ni}_{\mathrm{x}} \mathrm{O}_{3-\delta}$ perovskite films. Sensors and Actuators B: Chemical, 54, 236-242 (1999).

6. Chiu, C. and Chang, Y. H. The structure, electrical and sensing properties for CO of the $\mathrm{La} 0.8 \mathrm{Sr} 0.2 \mathrm{Co}_{1-\mathrm{x}} \mathrm{Ni}_{\mathrm{x}} \mathrm{O}_{3-\delta}$ system. Materials Science and Engineering: A, 266, 93-98 (1999).

7. Tsipis, E., Kiselev, E., Kolotygin, V., Waerenborgh, J., Cherepanov, V. and Kharton, V., Mixed conductivity, Mössbauer spectra and thermal expansion of (La, $\mathrm{Sr})(\mathrm{Fe}, \mathrm{Ni}) \mathrm{O} 3-\delta$ perovskites. Solid State Ionics, 179, 2170-2180 (2008).

8. Chiba, R., Yoshimura, F. and Sakurai, Y., Properties of La 1-y $\mathrm{Sr}_{\text {y Ni-x }} \mathrm{Fe}_{\mathrm{x}} \mathrm{O}_{3}$ as a cathode material for a low-temperature operating SOFC. Solid State Ionics, 152, 575$582(2002)$

9. Khalil, M.S., Synthesis, X-ray, infrared spectra and electrical conductivity of La/BaCoO3 systems. Materials Science and Engineering: A, 352, 64-70 (2003).

10. Khalil, M.S. and El-Sayed, A., The influence of Li substitution on the structure, electrical and magnetic properties of $\mathrm{La} / \mathrm{BaCoO} 3-\delta$, Polish Journal of Chemistry, 80 1523-1532 (2006).

11. Khalil, M.S., Influence of Iron Content on the Electrical and Dielectric Properties of $\mathrm{La} 0$. 7Ba0. 3Co1- $\mathrm{yFeyO}_{3}$. Zeitschrift für Physikalische Chemie/International Journal of Research in Physical Chemistry and Chemical Physics, 217, 1387-1398 (2003).

12. Pechini, M., US Patent\# 3.330. 697, US Patent, 3.330. 697, (1967).

13. Dinnebier, R.E., Powder diffraction: theory and practice, Royal Society of Chemistry, (2008).

14. Ganguly, P., Vasanthacharya, N., Rao, C. and Edwards, P., Composition-controlled metal-insulator transitions and minimum metallic conductivity in the oxide systems $\mathrm{LaNi}_{1-} \mathrm{MxO}_{3}(\mathrm{M}=\mathrm{Cr}, \mathrm{Mn}, \mathrm{Fe}$, or Co). Journal of Solid State Chemistry, 54 (1984) 400-406.

15. Blasco, J. and García, J., Structure, magnetic and electrical properties in $\mathrm{Nd}_{1-} \mathrm{La}_{\mathrm{x}} \mathrm{NiO}_{3}$ system. Solid State Ionics, 63, 593-598 (1993).

16. West, A.R. Solid State Chemistry and Its applications, John Wiley \& Sons, 2007. DOI: $10.1021 / \mathrm{cm} 9806681$

17. Khalil, M. S. Influence of Iron Content on the Electrical and Dielectric Properties of $\mathrm{La} 0$. 7Ba0. 3Co1-yFeyO3. Zeitschrift für Physikalische Chemie/International Journal of Research in Physical Chemistry and Chemical Physics, 217, 1387-1398 (2003a). DOI: $10.1524 /$ zpch.217.11.1387.20489.

18. Khalil, M. S. Synthesis, X-ray, infrared spectra and electrical conductivity of La/Ba$\mathrm{CoO} 3$ systems. Materials Science and Engineering, A, 352, 64-70 (2003b). Doi: 10.1016/S0921-5093(02) 00557-9. 
19. Khalil, M. S. and El-Sayed, A. The influence of Li substitution on the structure, electrical and magnetic properties of $\mathrm{La} / \mathrm{BaCoO} 3-\delta$. Polish Journal of Chemistry, 80, 1523-1532. ISSN: 0137-5083 (2006).

20. Kim, D. J., Shen, D., Yoon, S. H. Choe, S. Y. and Kaufman, D. Y. (2008) Effect of $\mathrm{Ru}$ and $\mathrm{LaNiO} 3$ barrier layers on lead zirconate titanate films grown on nickel-based metal foils by sol-gel process. Ceramics International, 34, 1261-1265. doi:10.1016/j.ceramint.2007.03.017.

21. Lima, S. M. d. and Assaf, J. M. Synthesis and Characterization of $\mathrm{LaNiO}_{3}, \mathrm{LaNi}_{(1-}$ ${ }_{\mathrm{x})} \mathrm{Fe}_{\mathrm{x}} \mathrm{O}_{3}$ andLaNi $\mathrm{Li}_{(1-\mathrm{x})} \mathrm{Co}_{\mathrm{x}} \mathrm{O}_{3}$ Perovskite Oxides for Catalysis Application. Materials Research, 5, 329-335. (2002)http://dx.doi.org/10.1590/S1516- 14392002000300018.

22. Pechini, M. US Patent\# 3.330. 697. US Patent, 3.330. 697 (1967).

23. Tsipis, E., Kiselev, E., Kolotygin, V., Waerenborgh, J. Cherepanov, V. and Kharton, V., Mixed conductivity, Mössbauer spectra and thermal expansion of $(\mathrm{La}, \mathrm{Sr})(\mathrm{Fe}, \mathrm{Ni}) \mathrm{O}_{3-\delta}$ perovskites. Solid State Ionics, 179, 2170-2180 (2008) doi:10.1016/j. ssi. 2008.07. 017.

24. West, A. R. Solid State Chemistry and Its Applications. John Wiley \& Sons. ISBN: 8126511079 (2007)

(Received 12/2/2016;

accepted 28/7/2016) 